\title{
Algunas reflexiones en clave sucesoria sobre la mancomunidad testamentaria y el poder testatorio en el Código Civil cubano
}

\author{
Some reflections on the testamentary commonwealth and testamentary power as \\ testatory mechanisms in the Cuban Civil Code.
}

JOANNA PEREIRA PÉREZ ${ }^{1}$

Universidad de La Habana, Cuba

RECEPCIÓN: 06/03/2017• ACEPTACIÓN: 01/05/2017

RESUMEN: Sobre la mancomunidad testamentaria y el poder testatorio han existido de antaño estigmas en torno a que su puesta en práctica vulnera lo que la doctrina ha reconocido como caracteres fundamentales del negocio jurídico testamentario: por una parte, su carácter personalísimo y, por el otro, la prohibición de la testamentifacción conjunta. En este contexto se reflexiona sobre la utilidad de ambas figuras, y las ventajas que reporta en los ordenamientos jurídicos que las permiten, a la par de los riesgos que su utilización genera para los testadores y para la seguridad jurídica en general. Se enfatiza en la exégesis de la normativa cubana y su implicación para la práctica notarial. Como conclusión se proponen alternativas que disminuyen los riesgos ante su utilización y potencian una mayor autonomía de la voluntad de las personas en sede sucesoria.

1. Abogada. Académica de Derecho Civil Parte General y Derecho Sucesiones de la Facultad de Derecho de la Universidad de La Habana. Notario en ejercicio. Máster en Bioética por el Centro de Estudios de Bienestar y Salud Humanos de la Universidad de La Habana. Participación como ponente en eventos internacionales. Varias publicaciones en libros y revistas. Cursa actualmente el Doctorado en Ciencias Jurídicas en la Universidad Rey Juan Carlos de Madrid con una beca completa de doctorado de la Fundación Carolina. Correo electrónico: joanna@lex.uh.cu. 
PALABRAS CLAVE: Carácter personalísimo del testamento - testamento mancomunado - poder testatorio - revocación.

ABSTRACT: Traditional stigmas have attached to testamentary commonwealth and testamentary power, since their implementation violates aspects of testamentary law recognized in the doctrine as fundamental: on the one hand, the highly personal character of testation and on the other, the prohibition of joint testation. In this context, we reflect on the utility of these legal mechanisms, and the advantages that they provide in legal systems where they are allowed, along with the risks that their use generates for testators and for legal safety in general. Emphasis is placed on exegesis of Cuban legislation and its implications for notarial practice. In conclusion, alternatives are proposed that reduce the risks involved in their use and promote a greater autonomy for people to express their will in matters affecting their legacy.

KEY WORDS: Personal character of the will (testament) - Joint testation Testamentary power - Revocation.

\section{Introducción}

Sobre la mancomunidad testamentaria y el poder testatorio han existido de antaño estigmas en torno a que su puesta en práctica vulnera dos aspectos muchas veces reconocidos por la doctrina como caracteres fundamentales del negocio jurídico testamentario: por una parte, su carácter personalísimo y, por la otra, la prohibición de la testamentifacción conjunta.

Según la técnica empleada por el legislador del Código Civil cubano, el artículo 477 se ubica dentro de las Disposiciones Generales de la Sucesión Testamentaria, correspondientes al capítulo I, del título II del libro cuarto, a continuación de regular en el artículo 476 al testamento, y solo después del título I, dedicado a las disposiciones generales, lo cual, a nuestro juicio, es acertado, máxime si tenemos en cuenta que la esencia personalísima y la mancomunidad son caracteres generales dentro de la materia testamentaria, así reconocidos y estudiados por la mayoría de los civilistas².

2. Vid. Roca-Sastre (2002), pp. 84-87; Díez-Picazo y Gullón (1998), pp. 332-333; Delgado de Miguel (2005), pp. 41-49; Fernández (2000), pp. 9-17; Maffia (1987), pp. 150-157; Ossorio (2001), p. 25-29; GARRIDO (2000), pp. 207-211. 
Resulta relevante señalar en estas notas introductorias, que a contrario sensu de la generalidad de las normas reguladoras de la sucesión testamentaria, los aspectos que reseñamos, se configuran como una prohibición legal, en un ámbito donde prima la libertad de testar como principio y donde le es permitido a la persona un amplio despliegue de su autonomía de la voluntad, debido a la propia naturaleza del testamento como negocio jurídico, debido a lo cual es común, que con excepción de las contadas legislaciones que permiten el testamento por comisario o a través del negocio jurídico de apoderamiento ${ }^{3}$ y aquellas que estipulan los testamentos mancomunados ${ }^{4}$, la mayoría de los códigos civiles foráneos las disciplinen como normas de iuscogens y en forma de prohibición ${ }^{5}$.

El artículo 477 del Código Civil de Cuba, aborda dos temáticas diametralmente opuestas, aunque relacionadas en su tronco común, es por ello que proponemos analizarlas en dos partes y en el mismo orden en que aparecen refrendadas en el precepto en comento. Siguiendo esta lógica, desarrollaremos dos planos de las instituciones objeto de estudio: por una parte, sus aspectos doctrinales más relevantes y, por otra, la forma en que han sido llevadas a la ley, o sea, su traducción normativa.

Continuando esta línea de pensamiento, es dable anotar que el legislador cubano unificó en un solo artículo, aunque en dos apartados independientes, aspectos que el Código Civil español, predecesor del cubano, regula en artículos diferentes. Consideramos que ello puede, deberse en primer lugar, a que ambos son caracteres del testamento y deseó agruparlos como tal, y en segundo orden, a que el autor de la norma cubana simplificó notoriamente su forma de regulación, debido a lo cual ya no era necesario dedicarle normas autónomas ${ }^{6}$.

3. Proponemos se consulte el Código Civil de Bolivia, artículos 469 a 478. En la legislación civil española, las compilaciones de Derecho Foral regulan distintas modalidades del poder testatorio, así lo encontramos en Cataluña. Navarra, Aragón, Baleares y Vizcaya y Alava, para abundar consúltese: SERRANO (1978-2002), pp. 119-120.

4. Para el caso de los testamentos mancomunados de obligada consulta es el Código Civil alemán, que permite su otorgamiento a partir de lo estipulado en los artículos del 2265 al 2270. De igual forma lo permiten en sus diferentes variantes las Compilaciones Forales españolas mencionadas anteriormente, modalidades que analizaremos en el desarrollo del presente comentario.

5. Se recomienda consultar los códigos civiles vigentes en: Alemania conocido como $B G B$ en sus parágrafos 2064 y 2065, Italia (arts. 631 y 632), Francia (art. 32), Portugal (art. 2182), Argentina (arts. 3619 y 3711), Brasil (art. 1667, IV) y Uruguay (art. 782), entre otros.

6. Vid. Código Civil español vigente:

Artículo 669. No podrán testar dos o más personas mancomunadamente, o en un mismo instrumento, ya lo hagan en provecho recíproco, o en beneficio de un tercero.

Artículo 670. El testamento es un acto personalísimo: no podrá dejarse su formación, en todo ni en parte, al arbitrio de un tercero, ni hacerse por medio de comisario o mandatario. Tampoco 
Resulta interesante, además, que se invirtiera el orden en que se presentan dichas prohibiciones, ya que en el caso cubano, primero se estipula el carácter personalísimo y a posteriori la negativa de mancomunidad, mientras que el legislador hispano lo estableció al revés y, aunque parezca una cuestión sin demasiada importancia, puede ser relevante en relación con la coherencia y sistemática de las normas, ya que, si bien son caracteres independientes de los actos de última voluntad, se encuentran estrechamente relacionados, pues sería incoherente prohibir la representación en sede testamentaria, en aras de proteger la última voluntad del causante, y en paralelo permitir que dos o más personas testen en un mismo instrumento, con todo lo que ello implica para la naturaleza y eficacia del negocio jurídico testamentario, puesto que como señala Ossorio, en ocasión del comentario que realizara al artículo 670 del Código Civil español: "En definitiva, se quiere evitar que el testamento deje de ser un acto de voluntad de su autor (causante de la sucesión), convirtiéndose en uno debido a la voluntad, total o parcial, de otra persona"7.

\section{El carácter personalísimo del negocio jurídico testamentario}

Primeramente, es importante acotar, qué debemos entender por carácter personalísimo del negocio jurídico testamentario y el alcance que ha de tener esta característica, para luego desentrañar el sentido de la norma y algunos de los supuestos más polémicos en los que puede ser trascendente su aplicación.

En este sentido señala Maffía: “El testamento es un acto estrictamente personal, es decir, que la voluntad debe ser expresada personalmente por el testador, y no por otra persona" 8 y coincidimos con Ossorio cuando asevera que tal característica constituye una clara excepción en el ámbito de la teoría general del negocio jurídico, en el que mediante el mecanismo representativo es posible su realización por persona diferente a aquella que por su virtud ha de resultar afectada ${ }^{9}$. Con igual criterio se manifiesta Barros Errazuriz al señalar que por regla general, una persona puede conferir poder a otra para que la represente en un acto jurídico, delegándole sus facultades. Pero siendo el testamento un acto de

podrá dejarse al arbitrio de un tercero la subsistencia del nombramiento de herederos o legatarios, ni la designación de las porciones en que hayan de suceder cuando sean instituidos nominalmente.

7. OSSORIo (2001), p. 116.

8. Maffía (1999), p. 154.

9. OsSORIo (2001), p. 115. 
excepcional importancia, en el que se manifiesta la última voluntad del testador, no cabe intervención de otra persona ${ }^{10}$.

No podríamos dejar de traer a colación las cavilaciones realizadas por Celaya en ocasión de la monografía que realizara sobre el testamento por comisario ${ }^{11}$, y en la que recoge los más acertados criterios doctrinales de la época en torno al tema. Como defensores del riguroso carácter personal del testamento resalta BoneT cuando defiende que tiene que ser un acto personalísimo, pues la voluntad no es delegable; iguales derroteros manifiesta seguir Manresa al expresar que ninguna defensa tiene el testamento por comisario ante la ciencia, ni aun ante la mera conveniencia o utilidad de la figura; continúa Puig Peña esta postura y la completa al reseñar que el testamento debe representar íntegramente la voluntad del testador y no puede tener mejor intérprete, que el testador mismo.

Con interesantes argumentos en sentido contrario, y en defensa de la eliminación de tan severa prohibición, se sitúa Celaya, quien esgrime en primer orden que la voluntad del testador podrá ser razón bastante para que la ley admita esta forma de testar, y el recurso a superiores principios filosóficos, algo misteriosos, no convence cuando se trata de enjuiciar una realidad social que no descansa sobre la lógica abstracta, postura que consolida argumentando que cualquier persona puede otorgar poderes de la amplitud que quiera, y no se ve con escándalo que el apoderado disponga de los bienes en vida del testador, cuando puede causarle perjuicios directos. Parece, pues, justo que a cualquier persona se le permita nombrar un delegado que, después de su muerte, con mejor información y completa libertad, distribuya sus bienes ${ }^{12}$.

Todo lo anterior nos lleva a concluir que, si bien es cierto que ningún estudioso del Derecho de Sucesiones discute el carácter personalísimo que debe tener el acto jurídico testamentario, sí han existido y existen excepciones, como reflejo de realidades sociales complejas, donde los propios seres humanos, inspiradores de las normas, han considerado oportuno suavizar el rigor con que siempre ha sido tratada esta característica, es por ello que a continuación razonaremos en torno a la controvertida figura del testamento por comisario.

10. Barros (1931), p. 125.

11. Celaya (1972), pp. 735-782.

12. Celaya (1972), pp. 744-747. 


\subsection{El poder testatorio y el testamento por comisario}

Una primera y muy somera definición del testamento por comisario es la dada por Sánchez Román cuando señala que "es aquel otorgado por una persona a nombre de otra, en virtud del poder que esta le confiere", afirmación que adolece, al decir de Celaya, de no señalar que estea forma testamentaria solo podrá ser utilizada por el comisario, una vez fallecido el comitente.

Se precisa, entonces, el testamento por comisario, como aquel en virtud del cual puede otra persona completar las disposiciones del testador, designando a su arbitrio las personas beneficiadas, salvo el caso del asignatario modal a quien se deja algo para que teniéndolo por suyo lo aplique a ciertos fines, que el mismo testador debe expresar, pero solo después de su fallecimiento.

Así, el poder testatorio es primero en el tiempo y es aquel en virtud del cual una persona otorga facultades representativas a otra para que disponga de los bienes del poderdante para después de su muerte, ergo si no existe el poder testatorio, no podrá ver la luz a posteriori el testamento por comisario.

Visto lo anterior nos corresponde cuestionarnos en primer término, si la prohibición expresamente formulada en el artículo que comentamos, alcanzará a todos los tipos testamentarios que reconoce el Código Civil cubano ${ }^{13}$, a lo que respondemos de manera afirmativa, pues donde la ley no distingue no cabe distinguir y es claro el legislador cuando dice "el testamento" sin diferenciar entre común o especial, y menos aún entre las formas a través de las cuales cada uno puede concretarse.

Tampoco establece nada el redactor de la norma, en cuanto a otros aspectos de la sucesión a saber, como son el contenido de la disposición testamentaria (típica o atípica), el tipo de atribución (universal o particular), la forma de división de la herencia, el nombramiento de albaceas, etc., de tal manera que el manto prohibitivo cubre todos los aspectos sobre los que pudiera materializarse la libertad de testar: a contrario sensu del Código Civil español, que sí delimita los aspectos sobre los que no podrá decidir un apoderado o mandatario ${ }^{14}$.

13. En virtud de lo preceptuado en el artículo 484 del Código Civil cubano se reconocen como comunes: el testamento notarial, el ológrafo y el consular y como especiales: el militar, el otorgado a bordo de nave o aeronave y el otorgado ante inminente peligro de muerte.

14. Vid. supra nota 6. 
En resumen, y siguiendo a Puig ${ }^{15}$, no se podrá dejar al arbitrio de un apoderado o tercera persona, ni la confección ni la vida del testamento, así como tampoco la facultad distributiva que es intransferible y permanece en cabeza del causante.

El clásico ejemplo de excepcionalidad a esta rigurosa regla latente en la mayoría de los códigos civiles vigentes, lo constituyen las legislaciones forales españolas, a las que nos referiremos seguidamente, a la par de las disímiles maneras en que pueden presentarse el poder testatorio y el testamento por comisario.

Antes de profundizar en las modalidades y formas en que dichas legislaciones han reconocido y permitido la utilización en el tráfico jurídico de ambas instituciones, se impone explicar su naturaleza jurídica y las teorías que ha defendido la doctrina al respecto.

Una primera línea es la que defiende que el comisario es un simple portador de la voluntad del testador, su función única consistirá en recibir el encargo del causante y manifestarlo en el momento oportuno, el testamento lo hizo ya el causante, por lo que el comisario no testa, sino que simplemente mantiene en reserva la declaración que se le hizo de manera privada, hasta que llegue el momento de hacerla pública. Diferente es el caso en el que se encomienda al comisario que designe de forma libre al heredero, precisamente porque el testador no se halla en condiciones de hacer una elección acertada. Un verdadero problema que se presenta en estos casos, y al que también alude Roca, es que mientras el comisario no utiliza su facultad de elegir, los bienes se encuentran en una situación de incertidumbre, porque los herederos no son conocidos ni pueden serlo hasta que el poder de testar sea utilizado, de ahí la diferencia con el ejemplo anterior, en virtud del cual el denominado heredero de confianza se limita a transmitir una voluntad previamente determinada por el testador, mientras que en el segundo de los casos, es el comisario, según interés familiar, amical o de afección y sustentado en la confianza, quien decidirá el heredero ${ }^{16}$.

\section{Modalidades del poder testatorio según las Compilaciones Forales españolas ${ }^{17}$}

Del estudio de las compilaciones de Cataluña, Aragón, Baleares, Vizcaya y Álava, y Navarra podemos identificar las siguientes modalidades:

15. PUIG (1954), p. 203.

16. Celaya (1972), pp. 737-739.

17. Vid. Compilaciones de Cataluña, Aragón, Baleares, Vizcaya y Álava, Navarra. 
a. Poder testatorio en virtud del cual se permite al cónyuge sobreviviente la institución de heredero entre los hijos comunes, o a dos parientes la facultad de seleccionarlo entre los hijos, aunque para el caso de los parientes también se exige de forma adicional la vecindad común.

b. Fiducia sucesoria conyugal o colectiva, a partir de la cual se permite nombrar al cónyuge o a dos o más parientes, para que ordenen la sucesión del testador, la diferencia con la anterior es que no limita el nombramiento solo a los hijos.

c. Heredero distribuidor, se puede delegar la facultad de distribuir determinados bienes adquiridos, ya sea libremente o con limitaciones, entre parientes del testador e, incluso, del distribuidor.

d. Poder testatorio puro, en cuya virtud el causante confiere al comisario la facultad de disponer de sus bienes tras su fallecimiento, sin limitaciones establecidas de manera legal.

e. Fiduciario comisario, que a modo de delegado del causante, puede instituir heredero o donatario universal, así como señalar dotaciones y disponer por el otro, a modo de legados.

Nótese que para nada es un simple poder, sino que en la mayoría de los casos, el legislador establece parámetros, sobre todo de índole subjetiva, de tal forma que el apoderado no podrá ser cualquier persona, sino solo el cónyuge u otro pariente, los cuales en ocasiones no podrán elegir entre extraños u otros familiares, sino solo entre los hijos, aspectos que tienden a proteger la presunta voluntad del testador, mutatis mutandi, tal y como ocurre con la sucesión intestada cuando la ley intenta establecer un orden sucesorio justo y en atención a que los afectos descienden, ascienden y se extienden.

Curioso resulta lo estipulado en el artículo 671 del Código Civil español, reconocido por la doctrina civil hispana como una clara excepción ante la prohibición que hemos venido comentando, ya que se le brinda al testador la posibilidad de encomendar a un tercero, tan siquiera debe ser un apoderado, la distribución de las cantidades que deje en general a clases determinadas, y establece un catálogo a manera de ejemplos: los parientes, los pobres, los establecimientos de beneficencia, así como la elección de las personas o establecimientos a quienes aquellas deban aplicarse. Otro ejemplo lo constituye el artículo 830 del propio cuerpo legal, cuando dispone que la facultad de mejorar no puede encomendarse a otro, pero entonces el 831 permite ordenar en testamento o en capitulaciones, que muriendo el cónyuge 
otorgante pueda el viudo o viuda que no haya contraído nuevas nupcias distribuir, a su prudente arbitrio, los bienes del difunto y mejorar en ellos a los hijos comunes, sin perjuicio de las legítimas y de las mejoras y demás disposiciones del causante ${ }^{18}$.

\section{2. ¿Apoderado o tercera persona?}

Sin perder el objetivo al que una investigación como la presente nos llama, reza dicho precepto que el testador no podrá dejar la formación del testamento al arbitrio de un apoderado o tercera persona, cabría entonces cuestionarse quién o quiénes pueden ser considerados como tales.

Esta polémica, transita en primer lugar, por la encomienda realizada a otra persona con instrucciones concretas, o sea, habiendo otorgado el testador a la par de su negocio de última voluntad, un negocio jurídico de apoderamiento, lo cual a la luz de la normativa civil cubana navega a contracorriente, ya que subyace una doble prohibición, en un sentido y siguiendo la definición de poder testatorio dada en líneas anteriores, no puede ninguna persona conceder facultades representativas para que otra otorgue un testamento en su nombre e interés. Por otra parte y observando con lente sistémico el cuerpo legal civil cubano, en virtud de nuestro ordenamiento la posibilidad de un poder cuyas facultades sean ejercitadas luego de la muerte del representado queda fuera de toda posibilidad si tenemos en cuenta que una de las causas de extinción del poder, establecidas en el artículo 409 en relación con el 414.2, es la muerte del poderdante.

Así salta a la palestra la diferencia entre apoderado y tercero, la cual radica en que al primero se dan órdenes o facultades precisas, y existe un negocio jurídico de apoderamiento previo contenido en documento público, mientras que con el tercero no tiene por qué mediar tal condición, y habiendo quedado vedada por completo la primera, es menester cuestionarnos en este punto, el concepto de tercero, que extrapolado de la teoría contractual al negocio testamentario nos lleva, sin más tribulaciones, a la consideración como tal, de todo aquel que no sea la persona del testador, siendo intrascendente a tales efectos la condición de sucesor, de sujeto completamente ajeno al mecanismo sucesorio o de ejecutor de últimas voluntades (albacea). En este sentido explica García que "el cargo de comisario se refiere a

18. En este sentido, resulta vasto el análisis que realiza Ossorio de las posibles excepciones que pudieran existir, como pueden ser: la facultad del heredero de determinación frente a un legado genérico y la facultad otorgada a uno de los herederos para realizar la partición hereditaria denominándolo comisario. Vid. Ossorio (2001), pp. 121-125. 
la formación del testamento, y no a la ejecución", y es por eso que no podemos considerar al albacea como un apoderado.

\subsection{Argumentos a favor y en contra}

Abordar los argumentos que se han esgrimido a favor y en contra del poder testatorio, es una forma de sistematizar las ideas hasta aquí expuestas y en todo caso son dos caras de una misma moneda, ya que los aspectos que se le imputan como negativos van de la mano de las no pocas ventajas que reportaría su implementación. Aunque es difícil acostumbrarse a la idea de que el testamento, de manera excepcional, ceda en su carácter personalísimo, en determinados casos y sobre todo en aquellos cuerpos legales donde está permitido su otorgamiento, se ha demostrado su factibilidad en la misma línea en que siempre ha sido útil la representación para ampliar la esfera de actuación de las personas.

La vulneración del carácter personalísimo del testamento y los riesgos que importa a los efectos de la existencia de voluntades captatorias, así como el hecho de que en el momento en que este poder despliega su eficacia ya no podemos preguntar o indagar con el poderdante-testador, acerca de los límites y alcance de las facultades otorgadas, más allá de lo que haya declarado en el negocio de apoderamiento, ha sido el más antiguo y compartido criterio en contra de la utilización del poder testatorio y del testamento por comisario. Argumentos que se refuerzan con la imposibilidad de una ratificación ante una gestión sin mandato o una gestión que se exceda de las facultades otorgadas por parte del causante al comisario.

Ante tales desventajas, como ya hemos estudiado anteriormente, los ordenamientos jurídicos han respondido matizando el poder testatorio o el testamento por comisario en algunos aspectos, ya sea limitando los sujetos que pueden ser designados como apoderados o aquellos entre los que el apoderado puede decidir al sucesor, imponiendo requisitos adicionales a los representantes, como la vecindad común al testador o la existencia de vínculo matrimonial entre poderdante y apoderado. De igual forma se han limitado desde la norma, las facultades que este mandatario puede ejercer, ya que en determinados casos solo puede escoger entre los hijos del causante, o entre explícitos parientes establecidos en la ley. Otra forma de proteger a la última voluntad del causante de posibles abusos de los comisarios es que estos no tengan la condición de causahabientes, ni se beneficien con atribución testamentaria alguna, salvando el conflicto de intereses, que trae a colación otra prohibición milenaria en materia de representación, que es la autocontratación, pero llevada en este caso a la materia sucesoria. 
Por último, y quizá el más fuerte de todos los argumentos a favor, es que la posibilidad de uso del testamento por comisario y el poder testatorio son una arista dentro del principio fundamental que informa al Derecho de Sucesiones y es que la voluntad del causante es la ley de la sucesión, se exprese como se exprese, ya sea porque la manifieste él mismo, o ya sea porque delegue en otra persona dicha posibilidad.

\section{La mancomunidad testamentaria, su prohibición en el Código Civil cubano}

Señala Gil, que en términos generales siguen sin conocerse a ciencia cierta los antecedentes remotos de este tipo testamentario ${ }^{19}$, y que a la postre la preocupación por este detalle ha provocado que se le identifique con instituciones como los pactos sucesorios, máxime si de cónyuges se trata ${ }^{20}$.

Por lo que respecta a su denominación, disímiles han sido las formas que se han usado para identificar esta institución, entre ellas encontramos: "mutuo", testamento "mancomún o de hermandad" 21 , o aquellas que resaltan la cualidad que modifica de los elementos de la relación jurídica sucesoria tales como "testamento subjetivamente plural"22, "testamento conjunto", "testamento colectivo" y "testamentifacción conjunta". Lo relevante es que todas resaltan el primero de los elementos fundamentales que define a este tipo testamentario, y es que deben existir dos o más manifestaciones de última voluntad, contenidas estas en un mismo instrumento -segundo aspecto de vital importancia-, ya sean en beneficio de un tercero o simplemente recíprocas.

En el entendido de García, lo relevante para definirlo es que exista un vínculo causal entre una pluralidad de declaraciones mortis causa contenidas en un mismo instrumento, independientemente de en provecho de quién se realice la declaración. Siguiendo esta línea debemos realizar una segunda distinción que aclara de manera acertada Barruetabeña, ya que un testamento mancomunado puede contener, liberalidades mutuas o disposiciones correspectivas, las que definirán, como estudiaremos más adelante, los diferentes tipos de testamentos mancomunados reconocidos.

19. Para un estudio pormenorizado de los orígenes y aspectos históricos del testamento mancomunado, véase BARRUETABEÑa (2013), pp. 25-34.

20. GIL (2011), p. 1214.

21. García (2006), pp. 289-290.

22. GIL (2011), p. 1214. 
Es notable que a la hora de fijar el concepto de testamento mancomunado la doctrina es casi unánime en cuanto a sus caracteres definitorios y su consideración como negocio jurídico mortis causa y no como pacto sucesorio a pesar de las similitudes que ambos institutos poseen, siendo el punto conflictual los aspectos formales del instrumento sucesorio en sí mismo, la delimitación del ámbito subjetivo de la figura, o sea, quiénes pueden participar de esta particular relación jurídica y la posibilidad y diversas variantes en cuanto a la revocación de sus disposiciones, elementos sobre los que abundaremos seguidamente.

En conclusión, son aspectos esenciales en la definición de la testamentifacción conjunta, la pluralidad de otorgantes, en paralelo a la unidad de otorgamiento y de instrumento ${ }^{23}$, a lo que se añade la necesaria conexión que debe existir entre dichas manifestaciones de voluntad mortis causa. Ello nos lleva a desechar como acto de última voluntad conjunto, aquellos casos en que una persona otorgue testamento que a posteriori sea aprobado por otra como propio, violentando la unidad de acto; o cuando dos testadores ordenen sus disposiciones en dos instrumentos separados, pero coligados, no cumpliéndose en este supuesto la necesaria unidad instrumental. En este mismo orden de ideas, no es, a nuestro juicio, definitoria la unidad de contenido en las declaraciones de voluntad mancomunadas, ya que en el mismo instrumento pueden existir cláusulas comunes para ambos otorgantes y otras propias emanadas de la independiente voluntad de cada uno, aspecto que a la postre reviste especial importancia al momento del polémico análisis de la revocación cuando se utiliza esta manera de testar ${ }^{24}$.

Ilustradora resulta la opinión que vierte desde la doctrina patria Clavijo en 1991, a solo tres años de vigencia del actual Código Civil cubano que comentamos, y que, en ocasión de realizar algunas reflexiones y recuentos sobre este cuerpo legal, al referirse al testamento mancomunado comenta: "Lo traemos al ruedo porque se puja su reconocimiento. Donde en la práctica se ha hecho hincapié para su admisión ha sido con vista a los cónyuges, aunque no haya sido privativo de éstos. Se dice que después del reconocimiento de la amplia libertad de testar, de la legalidad de mancomunidad de las cuentas de ahorro bancarias, de la estipulación a favor de tercero y de la emancipación de la mujer (económica, cultural, política, etc.), habida como la contraparte débil en el acto jurídico por los prejuicios y discriminaciones de un pasado machista, ahora no se justifica la prohibición para que los cónyuges

23. Reconociendo categóricamente a la unidad instrumental como requisito indispensable del testamento mancomunado encontramos a Dí́zZ-PiCAZo y Gullón (1998), pp. 332-333.

24. Apud. Barruetabeña (2013), p. 49. 
puedan ser herederos correspectivos concurriendo ambos a otorgar el testamento en un solo acto o instrumento (aunque también puedan hacerlo dos o más personas a favor de un tercero)" 25 .

Dicho todo esto, si volvemos al tópico que analizamos, el legislador cubano estableció una prohibición que se caracteriza por vedar la unidad instrumental de manifestaciones de última voluntad provenientes de sujetos diferentes, por cuanto refiere que no pueden testar dos o más personas en un mismo documento, eliminando de la norma la referencia a la unidad de contenido, ya que pueden perfectamente, y de hecho en la práctica cubana ocurre, dos personas, por lo general cónyuges y padres de hijos comunes, disponer de sus bienes a favor de su descendencia, otorgando disposiciones testamentarias idénticas, pero en instrumentos diferentes. Por el contrario, el legislador del Código Civil español, sí hizo mención al contenido de las disposiciones testamentarias en el mismo precepto, pues la prohibición del artículo 669 comprende y aclara, que se extiende a los testadores que lo hagan en provecho recíproco o bien en beneficio de un tercero ${ }^{26}$.

Es por ello que en lo que al precepto cubano respecta, hay que hacer varias disquisiciones, ya que tanto como eliminó las diferencias en cuanto al contenido, el redactor de nuestra norma utilizó el término 'documento' y no el de 'instrumento’ como la norma española de la que trae causa. Ahora bien, si se entiende por documento aquel escrito que ilustra acerca de algún hecho, y el Diccionario de la lengua española distingue, entonces, entre documento privado como aquel que autorizado por las partes interesadas, pero no por funcionario competente, es prueba a favor de quien lo escribe o sus herederos; y el documento público, por su parte, lo define como aquel que es autorizado por funcionario competente para ello, que acredita los hechos que refiere y su fecha ${ }^{27}$, distinción que no realizó el redactor de la norma, ya que se refirió a documento a secas, sin cualificarlo como público o privado, somos del criterio que considera oportuno razonar como irrelevante tal cambio de denominación por parte del legislador y desentrañar que su verdadera intención no fue otra que reflejar la unidad documental como característica distintiva del testamento mancomunado. En esta misma línea autores como

25. Clavijo (1991) [en línea] disponible en http://vlex.com/vid/nuevo-codigo-civil-recuentoreflexiones-45046432. [Fecha de consulta: 28 de octubre de 2016].

26. Vid. España. Derecho de Sucesiones: Legislación, comentarios y jurisprudencia, aspectos civiles, procesales y fiscales (2007), pp. 43-44.

27. Real Academia Española (2014), p. 819. 
López y Barruetabeña, en sus monografías sobre el tema, utilizan indistintamente las categorías documento e instrumento ${ }^{28}$.

Como corolario podemos aseverar que la característica distintiva del testamento conjunto, tal y como lo refrendó nuestro legislador, es la unidad instrumental o lo que denomina Albaladejo como "unidad del acto de testar" ${ }^{29}$, por lo que no resulta trascendente que los testadores estén o no relacionados entre sí, sean independientes o no las disposiciones que se establezcan, o sean diferentes o iguales los beneficiaros instituidos sucesores.

\subsection{Tipos de testamentos mancomunados}

En términos generales, podemos afirmar que no son igualitarios los criterios doctrinales al momento de organizar y explicar los diferentes tipos o clases de testamentos mancomunados, dicho lo cual nos referimos a la forma que según nuestra consideración, representa a un mayor número de autores, aunque con pinceladas propias. En este orden, se reconocen diversas formas a través de las cuales puede presentarse el testamento mancomunado, siendo los más notables los siguientes criterios de diferenciación: en lo referente al contenido, pueden ser considerados los testamentos mancomunados como meramente simultáneos o correlacionados, recíprocos o mutuos, y los conjuntos, a lo que añade Gil Rodríguez los testamentos $\operatorname{mixtos}^{30}$.

Es así que los testamentos mancomunados simultáneos o correlacionados consisten en el otorgamiento en un único acto, de las últimas voluntades de varias personas sin que se establezca vinculación alguna entre las disposiciones mortis causa resultantes, o sea, no existe unidad en cuanto al contenido, pero sigue siendo testamento mancomunado por no vulnerarse los ya mencionados requisitos de unidad instrumental y de acto. En los testamentos mancomunados recíprocos o mutuos, los cotestadores se instituyen de manera mutua herederos o respectivamente testan uno en provecho del otro, pero siempre en un mismo instrumento. Sin embargo, los testamentos mancomunados conjuntos responden ante la posibilidad de que ambos disponentes instituyan como causahabientes a uno o varios terceros de común acuerdo.

28. LÓPEZ (2003), pp. 43-45.

29. Serrano (1978-2002), p. 103.

30. GIL (2011), p. 1217. 
Distinto de este criterio clasificatorio, es el que centra su interés en la relación de dependencia entre las diferentes disposiciones del testamento mancomunado y no en su contenido, en virtud de lo cual la doctrina expone su carácter de simultáneas o interrelacionadas. Las primeras, se identifican por poseer un mismo soporte instrumental, pero sin relación vinculante alguna entre sí; las segundas, se caracterizan por la existencia de una relación de dependencia, ya sea de manera conjunta, recíproca o correspectiva. En las conjuntas existe un criterio coincidente, pero una voluntad no es determinante para la otra, piénsese en el supuesto en que A y B están de acuerdo en instituir como heredero a Z; por el contrario, sería recíproca si $\mathrm{A}$ y $\mathrm{B}$ se instituyen como herederos el uno del otro; mientras que la correspectividad entraña vinculación y condicionamiento entre las disposiciones realizadas, es el caso en que cada testador se ha manifestado en consideración a lo establecido por el otro, creándose una situación de dependencia jurídica entre ambas manifestaciones de voluntad, siendo el ejemplo el caso en que $Z$ solo podrá reputarse heredero de $\mathrm{A}$, si $\mathrm{X}$ lo es de $\mathrm{B}$.

Aclara Fontanellas de forma acertada, que las manifestaciones de voluntad recíprocas son usualmente correspectivas, pero es fácil imaginar disposiciones correspectivas que no sean necesariamente recíprocas ${ }^{31}$.

Otro criterio clasificatorio lo constituye la cantidad de otorgantes, de tal suerte que si son dos, se le denominará testamento mancomunado doble, si por el contrario son más, será un testamento mancomunado plural. A lo que López añade una subdivisión a razón de si el mancomunado doble se otorga por cónyuges, por parientes o por personas no relacionadas entre sí. Interesante resulta en el orden práctico la subclasificación que realiza este autor de los testamentos mancomunados cuyas cláusulas sean correspectivas, explicando que pueden presentarse de manera unilateral o bilateral, o sea, que solo una de ellas dependa de la otra, o que posean una relación de dependencia dual. En este mismo orden distingue entre la correspectividad expresa y la tácita, asociado al significado que siempre se ha dado desde el derecho a estos términos y, por último, defiende la existencia de una correspectividad perfecta o imperfecta. En la primera, la existencia de la disposición de un cotestador se hace depender de la eficacia del otro; mientras que, en la segunda, su relación de dependencia se funda en circunstancias estipuladas que determinan la existencia de las disposiciones de uno de los testadores, y que de no producirse, entonces llevarían a la ineficacia de las disposiciones del otro.

31. Fontanellas (2013), p. 407. 
Por último, es dable significar que a contrario sensu de otros ordenamientos jurídicos civiles, nuestro legislador en la redacción del artículo objeto de este comentario no da elemento alguno que permita identificar algunas de las clasificaciones anteriormente enunciadas.

\subsection{Particular referencia a la revocación en sede de testamento mancomunado}

Uno de los tópicos que más cavilaciones ha propiciado en sede de testamento mancomunado es la revocación como forma de ineficacia testamentaria. En primer orden, porque los autores que se oponen a esta particular manera de testar utilizan el argumento de la imposibilidad de revocación como bandera, sobre todo por su vínculo con la naturaleza jurídica del testamento como negocio jurídico mortis causa, de última voluntad. Señalan, además, que al excluirse la posibilidad práctica de la revocación, la figura del testamento de hermandad se estaría alejando, en esencia, de lo que se conoce como testamento y acercándose a los denominados pactos sucesorios ${ }^{32}$.

A nuestro juicio, las posiciones extremas no aportan nada a un debate teórico y doctrinal, que a la postre debe revertirse en una verdadera utilidad práctica. Es por ello que a la interrogante acerca de si es posible revocar de forma total o parcial un testamento otorgado en mancomunidad, la respuesta es afirmativa, y así lo demuestran aquellas legislaciones que regulan y permiten el uso de esta institución, como mostraremos más adelante. Ahora bien, en lo que sí estamos de acuerdo, es en establecer reglas propias para dicha revocación cuando se navegue en las aguas de la mancomunidad, reglas que permitirán sanar aquellas deficiencias o peligros enunciados por los autores que se muestran como detractores de la figura y lo que es más importante, teniendo como punto de mira la protección de la que es la última voluntad de esa persona, con todo lo que ello significa en el orden personal, familiar, jurídico y social.

Vale aclarar que dado el sentido de nuestro comentario y sin perder de vista el objetivo, mostraremos los aspectos más relevantes que dejen sentadas las bases para futuras investigaciones, que con mayor profundidad estudien la temática y fundamenten una futura revisión legislativa. Los temas más peliagudos desde la perspectiva doctrinal se han dividido en diversas vertientes, por una parte, la forma

32. Apud. Fernández (2000); Fontanellas (2013); Barruetabeña (2013) y Arjona (2013). 
requerida para dicha revocación, en adición a las condiciones para la eficacia de la revocación y, por último, las marcadas consecuencias que en la ordenación sucesoria comportan.

Delgado sitúa la intención del legislador al establecer esta prohibición en el Código Civil español ligada a la salvaguarda de que el testamento sea revocado libremente por quien lo otorga. En esta misma línea se manifiestan Ossorio, Gil, Pothier, García Goyena ${ }^{33}$, Busto y López. Dicho esto, se complejiza mucho más el debate, porque, si bien es cierto que la mayoría de los autores reconocen a la revocación como la desventaja más acuciante del testamento mancomunado, el reconocerla, estudiarla y regularla genera disímiles problemáticas, que las legislaciones que han permitido el uso de esta institución las han tratado de solucionar de una u otra manera, con más o menos acierto.

Existe una primera precisión reseñada de manera magistral por Busto ${ }^{34}$, en relación con el efecto que genera la muerte de uno de los cotestadores de un testamento mancomunado para con el otro, siendo parte de la doctrina partidaria de considerar que se ha confirmado el testamento y, por consiguiente, es irrevocable por el sobreviviente; mientras otro sector, del que es vocero el autor citado, considera que no existe razón alguna para que el cotestador que sobrevive no pueda usar libremente su voluntad revocatoria.

El segundo punto álgido gira en torno a la forma en que ha de proceder la revocación, mostrándose casi unánime la doctrina en considerar a la notarial como la manera idónea de articularla, debido fundamentalmente a la publicidad que debe dársele al acto revocatorio para con el correspondiente cotestador. Posición doctrinal que pierde sustento cuando el testamento mancomunado se articula a través de un ológrafo, unido al paradigma de que la revocación deberá tener las mismas formalidades que las utilizadas para otorgar el testamento cuyas disposiciones son objeto de revocación. Solución salomónica es la estipulada por el Código Civil alemán, que además de permitir el testamento mancomunado y en específico el mancomunado ológrafo, aunque ambos limitados solo a los cónyuges, resuelve el escollo de la revocación, ya que los artículos del 2253 al 2258 establecen todos los aspectos relacionados con la revocación en general, sin figurar problema alguno en torno a la forma específica en que debe realizarse dicho acto revocatorio. Lo anterior se complementa con el artículo 2271 que

33. Citados por Busto (2003), p. 1558.

34. Op. cit., p. 1556. 
prohíbe la revocación unilateral de aquellas cláusulas correspectivas que estén contenidas en cualquier tipo de testamento mancomunado, e independiente de que la forma empleada sea la notarial o la ológrafa, estableciendo además reglas en lo relativo a la muerte de uno de los cotestadores al momento de oficiarse la revocación, dejando el cauce abierto para la revocación de cualquier otra cláusula que no posea esta naturaleza y a la que le será aplicable el régimen general de revocación de las disposiciones de última voluntad.

Como corolario de este tópico, no podemos dejar de mencionar, que, a la luz del Código Civil cubano, sería necesaria una profunda reforma en sede sucesoria, que no solo permitiera la utilización del testamento de hermandad en el contexto patrio sino que de manera sistémica lo armonizara con otros aspectos de especial relevancia, como el explicado anteriormente en relación con la revocación.

En lo relativo a las condiciones necesarias para la eficacia de la revocación, mencionan los estudiosos del tema que se debe partir de la premisa de si nos encontramos ante una revocación mancomunada, que no ofrece mayores inconvenientes ${ }^{35}$, o una revocación unilateral, a partir de la cual se disecciona la doctrina en dos posturas, los que consideran que no es loable por la vulneración que ello reviste para la voluntad ya manifestada por el cotestador fallecido, y los que defienden que sí pueda realizarse bajo determinados supuestos, que mencionaremos a continuación y que constituyen las condiciones necesarias para que la revocación unilateral sea válida en aquellos ordenamientos jurídicos que permiten el otorgamiento de testamentos mancomunados.

La notificación de la revocación realizada al cootorgante del testamento mancomunado, constituye el principal requisito de eficacia de la revocación unilateral de las disposiciones contenidas en estos tipos de actos de última voluntad, de tal suerte que la ausencia de notificación y la notificación realizada de manera inadecuada, conllevan a la nulidad del testamento revocatorio o de cualquier otra forma utilizada con tal fin. Su objetivo es notorio, pues el requisito de lo que está protegiendo es al cotestador que no ha revocado, ya que, a partir de la notificación, podrá tomar cuantas determinaciones estime conveniente en relación con la voluntad manifestada en el testamento mancomunado revocado. A lo anterior se

35. Salvo el cuestionamiento en torno a si esta voluntad revocatoria debe ser manifestada de forma expresa o también tendrán validez las formas tácita y presunta. Así como el debate en torno a si la forma de revocar la constituye el otorgamiento de sendos testamentos independientes por cada uno de los cotestadores del anterior mancomunado. 
suman otros aspectos relacionados con la notificación en sí misma, como son su forma, contenido y plazo para realizarla ${ }^{36}$.

Podemos aseverar entonces, que además de todas las problemáticas que genera el tipo testamentario mancomunado per se, la revocación provoca otras tantas, haciendo el tema mucho más conflictual.

\subsection{La mancomunidad testamentaria, luces y sombras}

Es imperativo, para concluir, las reflexiones traídas a colación sobre este tópico, y partiendo del hecho claro y rotundo de su prohibición en el ordenamiento jurídico civil cubano, con la consiguiente abstención notarial que ello provoca, que se enuncie en este punto, los argumentos que pueden ser utilizados por partidarios y detractores del testamento mancomunado en cualquier debate que sobre el tema se suscite.

Se ha apuntado como el primer y más antiguo argumento en contra del testamento conjunto, el hecho de que conculca con el carácter unipersonal del negocio jurídico testamentario. En este mismo sentido, si analizamos a lo interno nuestro Código Civil, es notable que el precepto comentado, está en total armonía con lo estipulado en el artículo 476 de este mismo cuerpo legal, cuando reza: "por el testamento, una persona...”, con lo cual, ya desde el alcance de esta norma el legislador cubano excluyó toda posibilidad de utilización del testamento mancomunado en la práctica jurídico civil patria.

Por su parte, García Goyena sostiene que la manera conjunta de testar atenta de forma directa contra la buena fe y la naturaleza del testamento, a lo que Albaladejo añade que las razones de la supresión han estado centradas fundamentalmente en que si el testamento mancomunado se declara irrevocable va contra la esencia del testamento, y si por el contrario se admite la revocación, en particular tras la muerte de uno de los otorgantes, se obra de forma injusta ${ }^{37}$.

Otra razón se ha sustentado en la posibilidad de voluntad captatoria entre los cootorgantes, argumento que se deja caer por sí solo si tenemos en cuenta que la

36. Para abundar en este tema vid. López (2003), pp. 202-235, Barruetabeña (2013), pp. 345-400, Gil (2011), pp. 1232-1235 y Busto (2003), pp. 1578-1585.

37. "Lo mejor es prohibir una forma de testamento incompatible con la buena fe (si es que se tolera la revocación de un testador, desconociéndolo o habiendo muerto el otro, que testó él como testó porque lo hizo como lo hizo el luego revocante), o con la naturaleza de los testamentos (si es que no se permite la revocación)". Albaladejo (1978-2002), pp. 107-108. 
presión la puede sentir de igual forma el testador al hacerlo de forma unipersonal, y que la consecuencia que ello provoca en el orden de la ineficacia del acto jurídico testamentario, podrá ser aplicada a uno u otro caso, sin distinción de la forma o manera en la que se haya otorgado el testamento.

Otra desventaja del orden práctico es la necesidad de determinar a qué otorgante es imputable cada cláusula de un testamento mancomunado, por lo que la hermenéutica testamentaria en función de la mancomunidad se tornará particularmente compleja.

A contrario sensu, se han apuntado como ventajas de este tipo testamentario en primer orden, las de índole familiar, aspecto intrínsecamente vinculado con la relación que ha tenido desde siempre la figura del testamento de hermandad con la institución del matrimonio, siendo notorio que aquellos ordenamientos donde es loable su utilización, se encuentre condicionada a la existencia del vínculo matrimonial entre las dos personas que se disponen a testar de forma mancomunada. Esta situación genera una posibilidad que a priori puede interpretarse como beneficiosa en el orden de la facilidad que representa para los cónyuges poder testar en un mismo instrumento jurídico a favor de su descendencia, o parientes por consanguinidad o afinidad $^{38}$, pero que en la práctica genera múltiples inconvenientes, sobre todo lo relacionado con la posterior disolución del vínculo matrimonial y la revocación de las disposiciones de este tipo, como ya hemos explicado anteriormente.

Volviendo al comentario que nos ocupa y teniendo en consideración todo lo dicho hasta aquí, es imperioso dejar sobre la mesa algunas interrogantes que bien pudieran propiciar sendas investigaciones y no pocos debates desde la academia y la práctica jurídica en Cuba. En este sentido, podríamos cuestionarnos si en virtud del ordenamiento jurídico cubano sería posible y ajustado a derecho, que dos personas testen mancomunadamente en un testamento ológrafo, y que a la postre en su proceso de adveración, este pueda ser considerado como dos testamentos válidos, para que la última voluntad de ambos se pueda hacer efectiva y teniendo como sustento el magno principio de la voluntad del causante como ley de la sucesión. Consideramos que no pocas problemáticas generaría tal supuesto, por cuanto habrían de tenerse en cuenta en primer orden el cumplimiento de los requisitos de forma de este tipo testamentario y, en segundo lugar, si al desligar ambas manifestaciones de voluntad en función de su eficacia, entonces pierden

38. En este sentido puede tener particular relevancia en el marco de las nuevas consideraciones doctrinales en torno a la denominada familia ensamblada. 
el sentido por el cual fueron otorgadas y se desvirtúa así, la voluntad que en su momento tuvieron los testadores.

Válido es también que nos preguntemos, si al amparo del ordenamiento jurídico cubano, podrían dos personas testar en instrumentos diferentes, pero hacer en ellos disposiciones correspectivas o recíprocas, en virtud de lo cual no infringen la norma en comento por no cumplirse el requisito de la unidad instrumental, que como ya se ha explicado, es indispensable para la mancomunidad ${ }^{39}$.

\section{Conclusiones}

A modo de conclusión, sirva todo lo dicho hasta aquí, como punto de partida para reflexiones más profundas en torno al tema del testamento mancomunado y, por otra parte, y en sentido contrario, para considerar la factibilidad y viabilidad práctica de la inclusión de cláusulas testamentarias con disposiciones recíprocas o correspectivas en la práctica notarial cubana, máxime si ha quedado demostrado en las líneas precedentes que no puede reputárseles como testamento mancomunado y, por lo tanto, no quedan bajo la sombra de la prohibición del artículo 469 de nuestra ley sustantiva civil.

\section{Referencias}

Alfonso Rodríguez, María Elvira (1966): "El testamento mancomunado”. En Revista Crítica de Derecho Inmobiliario. Número 633, marzo-abril, pp. 353-462.

Arjona Guajardo-Fajardo, José Luis (2013). “El reglamento UE n. 650/2012 y la ordenación de la sucesión "mortis causa” de los españoles de vecindad civil común mediante testamento mancomunado: breves notas sobre el tema”. En Revista Aranzadi de Derecho Patrimonial, Número 31, mayo-agosto, pp. 315-328.

Barros Errazuriz, Alfredo (1931): Curso de Derecho Civil. Cuarta edición corregida y aumentada (Santiago de Chile, Editorial Nascimiento, volumen v).

BARRUETABeÑa ZeneKorTA, Maite (2013): El testamento mancomunado o de hermandad en el Derecho civil del País Vasco (Valencia, Editorial Tirant to Blanch).

39. Explica Garrido que el testamento recíproco como el correspectivo, los cuales distingue del mancomunado, pueden hacerse en un mismo instrumento como en documentos separados. GARRIDO (2000), p. 207. 
Bellod Fernandez de Palencia, Elena (1997): El testamento mancomunado: estudios de documentos notariales aragoneses desde el siglo XVI hasta la actualidad (Zaragoza, Editorial El Justicia de Aragón).

Busto Lago, José Manuel (2003). “La sucesión testada en el Derecho civil propio de Galicia: el testamento abierto notarial, el testamento mancomunado y la delegación de la facultad de mejorar”. En Revista Crítica de Derecho Inmobiliario, Número 677, mayo-junio, pp. 1537-1618.

Celaya Ibarra, Adrián (1972). “El Testamento por Comisario”. En Anuario de Derecho Civil español, tomo xxv, fascículo III, julio-septiembre, pp. 735-782.

Clavijo Rivera, Fausto (1991). “El nuevo Código Civil de Cuba: Recuento y Reflexiones”. En: Revista Cubana de Derecho, Número 4, diciembre disponible en http://vlex.com/vid/nuevo-codigo-civil-recuento-reflexiones-45046432 [Fecha de consulta: 4 de octubre de 2016].

Delgado de Miguel, Juan Francisco (2005): Instituciones de Derecho Privado. (Navarra, Thomson Civitas, tomo v, volumen 2).

Real Academia Española (2014) Diccionario de la Lengua Española.

Díez-Picazo, Luis y Gullón, Antonio (1998): Sistema de Derecho Civil. Novena Edición (Madrid, Editorial Tecnos, volumen IV).

Fernández Hierro, José Manuel (2000): Los Testamentos (Granada, Editorial Comares).

Fontanellas Morell, Josep María (2013). “El testamento mancomunado en el Reglamento 650/2012 relativo a las sucesiones por causa de muerte”. En Borrás, Alegría, Forner Delaygua, Joaquim, González Beilfuss, Cristina y ViÑAS FARRÉ, Ramón. Entre Bruselas y La Haya: estudios sobre la unificación internacional y regional del Derecho internacional privado, "liberamicorum" (Madrid, Editorial Marcial Pons), pp. 405-415.

García Vicente, José-Ramón (2006): Derecho de Sucesiones Presente y Futuro. XI Jornadas de la Asociación de profesores de Derecho Civil (Murcia, Editorial Servicio de Publicaciones de la Universidad de Murcia).

Garrido Melero, Martín (2000): Derecho de Sucesiones, un estudio de los problemas a través del Código Civil y del Código de Sucesiones por causa de muerte en Cataluña. (Madrid-Barcelona, Editorial Marcial Pons).

Gil RodrígueZ, Jacinto (2011). “El testamento Mancomunado vasco, en perspectiva de unificación”. En Blasco Gascó, Francisco de P. Estudios jurídicos en homenaje a Vicente L. Montés Penadés (Valencia, Editorial Tirant Lo Blanch, tomo I), pp. 1209-1237.

López SuÁrez, Marcos A (2003): El testamento mancomunado en la Ley de Derecho civil de Galicia (Madrid, Editorial del Consejo General del Notariado). 
Maffía, Jorge O (1999): Manual de Derecho Sucesorio. Cuarta edición. (Buenos Aires, Editorial De palma, tomos I y II).

Ossorio Morales, Juan (2001): Manual de Sucesión Testada. Edición al cuidado de José Luis Monereo Pérez (Granada, Editorial Comares).

Puig Peña, Federico (1954): Tratado de Derecho Civil (Madrid, Editorial Revista de Derecho Privado, tomo v, volumen I).

Roca-Sastre Muncunill, Luis (2002): Derecho de Sucesiones. Segunda edición revisada, ampliada y puesta al día (Barcelona: Editorial Bosch, tomo I).

SÁncheZ-Rubio García, Alfredo (2012). "El testamento mancomunado aragonés". En Revista de Derecho Civil Aragonés, Número 18, pp. 121-161.

Tobajas Gálvez, Octavio (2000). "El testamento mancomunado en Aragón”. En Actualidad Civil, Número 18, 1 al 7 mayo, pp. 693-711. 